\title{
Understanding barium sulfate precipitation onto stainless steel
}

Franca Jones*, Phillip Jones†, Roland De Marco†, Bobby Pejcic\#, Andrew L. Rohlł†

*Corresponding author: AJ Parker Co-operative Research Centre for Integrated Hydrometallurgy Solutions, Nanochemistry Research Institute, Department of Applied Chemistry, Curtin University of Technology, GPO Box U1987, Perth WA 6845 Australia. Email: F.Jones@curtin.edu.au

\#CSIRO Petroleum, ARRC, PO Box 1130 Bentley WA 6102 Australia

+ iVEC, 'The hub of advanced computing in Western Australia', 26 Dick Perry Avenue, Technology

Park, Kensington WA 6151 Australia and Nanochemistry Research Institute, Department of Applied Chemistry, Curtin University of Technology, GPO Box U1987, Perth WA 6845 Australia.

$\dagger$ Nanochemistry Research Institute, Department of Applied Chemistry, Curtin University of Technology, GPO Box U1987, Perth WA 6845 Australia. 


\section{ABSTRACT}

This paper investigates the influence of barium sulfate scaling and scaling inhibitors on the electrochemical behaviour of stainless steel. The results of a synchrotron radiation grazing incidence Xray diffraction (SR-GIXRD) and electrochemical impedance spectroscopy (EIS) study on stainless steel shows that different scaling inhibitors interact uniquely with the substrate when barium sulfate is precipitated on the electrode surface. The main effect of the substrate in the presence of inhibitor is a tendency to form smaller barium sulfate particles. The SR-GIXRD patterns obtained in the presence of the two inhibitors were different to each other and to the control, with the carboxylate showing greater amounts of barite solids precipitated together with iron (III) and (II) sulfate, while the phosphonate showed low amounts of barite solid were precipitated. The presence of iron sulfates on the electrode surface as detected by SR-GIXRD, in the case of NTA, suggests that scaling inhibitors are not always benign, and can promote the dissolution of iron species from the substrate.

PACS codes: 81.10.Dn, 82.45.Bb, 84.37.+q, 82.80.Fk, 61.72.Ss, 68.55.Jk, 68.37.-d, 68.08.-p, 61.10.Nz

KEYWORDS barium sulfate, precipitation, scale, electrochemical impedance spectroscopy, inhibitors, morphology, interfaces, X-ray diffraction.

\section{INTRODUCTION}

While the impact of corrosion and scaling on industrial processes is well established [1, 2] work continues on understanding the fundamental electrochemical processes that are occurring. Not surprisingly, there is abundant literature in the fields of corrosion and scale formation [3, 4]. The investigation of how corrosion impacts on scale formation and vice versa has, to date, mainly 
determined the effect of calcium carbonate scale formation on a carbon steel surface [5-10]. It is unclear and unknown at this stage what influence (either synergistic or antagonistic), if any, corrosion inhibitors have on barium sulfate scale formation and/or barite scaling inhibitors have on corrosion behaviour. While it appears intuitive to suggest that the formation of a scale could be used to passivate the surface to corrosion [11-13], a rigorous and systematic investigation into the electrochemical behaviour of the surface of materials with and without the presence of different scales (and with inhibitors) is presently lacking, making this study warranted.

Most scaling occurs on surfaces that are metallic or metal alloys, thus it seemed obvious that both electrochemical investigations and surface characterization techniques would be necessary. In order to begin to address this issue, we present here a study of barium sulfate scaling onto stainless steel in the presence and absence of two scaling inhibitors.

Barium sulfate has been the focus of many investigations because it is a common scale, particularly in the production of oil on off-shore wells [14-16]. Barium sulfate, however, is also an ideal model system [17] due to its low solubility [18] and lack of polymorph formation under varied conditions. Stainless steel was chosen as it used in many industrial processes and because it has a low corrosion rate under these conditions [19]. As a starting point, we considered it important to minimise the effect of iron dissolution during barite scaling in order to later compare it to more reactive surfaces. In addition, the effect of two scale inhibitors was also investigated post and pre scale formation. The two inhibitors chosen reflect a difference in functional groups, as well as a minimal change in stereochemistry. They are nitrilotriacetic acid (NTA) and nitrilotrimethylenephosphonic acid (NTMP). The inhibitors contain three functional moieties attached by the same carbon atom spacing to a nitrogen atom. At room temperature, the phosphonate is a very good inhibitor of barite precipitation, while the carboxylate is less efficacious [20]. The similarity in stereochemistry is important, as it is believed that additives can inhibit precipitation via a so-called 'lattice matching' criterion [21, 22]. By minimising stereochemical differences, the difference in the two additives' properties (either in inhibiting precipitation or on 
corrosion) mainly reflects the difference in the functionality of the inhibitors. In addition, the impact of these inhibitors on the precipitation behaviour of barium sulfate has been thoroughly investigated [23, $24]$, thus, the effect of the substrate can be determined.

The technique of SR-GIXRD can be used to study in-situ the structural chemistry of solid-liquid interfaces [25-27]. The surface sensitivity of the SR-GIXRD technique is due to the incident X-ray beam undergoing total external reflection or extreme surface attenuation at angles of incidence below or near the critical angle. Thus, the beam skims across the surface analyzing the first few tens of nanometers of the sample surface. Furthermore, it has been possible to combine the SR-GIXRD structural chemistry technique with electrode kinetic measurements such as cyclic voltammetry (CV), amperometry and potentiometry [25-27]. For a more detailed discussion of this topic we direct the reader to ref $[13,28]$.

\section{EXPERIMENTAL}

\section{Scale formation onto the stainless steel electrode}

The cell used for investigating the formation of barium sulfate scale onto a stainless steel electrode by GIXRD is shown in Figure 1. Use of this cell for simultaneous electrochemical impedance spectroscopy (EIS) and SR-GIXRD measurements has been previously reported [12, 13]. The stainless electrode was polished before each experiment with a 1200 grade sandpaper using MilliQ water as lubricant. The reservoir volume was $400 \mathrm{~mL}$, the slurry was stirred at $600 \mathrm{rpm}$ and the temperature was $60{ }^{\circ} \mathrm{C}$. Barium chloride (AR grade, $1 \mathrm{~mL}$ of $0.1 \mathrm{M}$ ) was added to the reservior. When inhibitor was added, it was added prior to precipitation and to the barium chloride solution. The inhibitors used were NTMP and NTA (see Figure 2 for their structures). The inhibitors were added at a concentration of $\sim 0.02 \mathrm{mM}$ for NTMP and $\sim 0.05 \mathrm{mM}$ for NTA. In the case of NTA, the $\mathrm{pH}$ was 10 to ensure full de-protonation of the carboxylate

groups. The concentrations chosen balanced a desire to add only small concentrations of additives but 
achieve measurable inhibition in the subsequent precipitation of the barium sulfate scale. Sodium sulfate (AR grade, $1 \mathrm{~mL}$ of $0.1 \mathrm{M}$ ) was added after equilibration to temperature to commence the precipitation reaction. At $60{ }^{\circ} \mathrm{C}$ the equilibrium solubility is expected to be $\sim 1.44 \times 10^{-5} \mathrm{M}$, which results in an initial supersaturation ratio of 17.4 for the precipitation reaction. The solution was pumped from the reservoir through the cell at a flow rate of $22 \pm 1 \mathrm{~mL} / \mathrm{min}$ using a Masterflex peristaltic pump.

In-situ SR-GIXRD was performed on Beamline 20B at the Photon Factory in Tsukuba Japan using the "BIGDIFF" diffractometer as described previously $[12,13,28]$. This facility supplies highly monochromatic $1 \AA$ X-rays by using a Si(111) channel cut monochromator. The parallel beam optics leads to a beam with dimensions of $100 \mu \mathrm{m}$ and $2 \mathrm{~mm}$ in the vertical and horizontal directions respectively. SR-GIXRD patterns were recorded using Fuji imaging plates for a data collection time of 20 minutes, using a grazing incidence angle $\theta$ of $0.5^{\circ}$ and $2 \theta$ angles between 0 to 45 (step size of 0.01 $\left.{ }^{\circ}\right)$. Under these conditions, below or near the critical angle, the beam is totally externally reflected or extensively attenuated and the technique is surface sensitive. The surface depth probed by the X-ray photon is approximately $230 \mathrm{~nm}$. Further details can be found in reference [13]. This makes SR-GIXRD particularly useful for the study of surfaces/thin films [29, 30].

The diffraction pattern of the electrode (Figure 3) with Kapton film consists of broad peaks reflecting the amorphous Kapton film structure (at $\sim 9.6,14.3$ and $17.5^{\circ} 2 \theta$ ), the presence of $\gamma$-Fe as a minor phase (PDF file number 52-0513, at $\sim 27.6$ and $\sim 31.7^{\circ} 2 \theta$ ) and the presence of a Ni-Cr-Fe major phase (PDF file number $35-1375$, at $\sim 28$ and $\sim 40^{\circ} 2 \theta$ ) within the stainless steel electrode. There remained one weak and broad peak that we were unable to assign at a $2 \theta$ angle of $\sim 24^{\circ}$. These peaks correspond to the native electrode in solution (or to the Kapton film). However, in the presence of barium sulfate it is possible that new electrode species are formed due to changes in the electrochemistry at the electrode surface. The SR-GIXRD patterns showed systematic errors in $2 \theta$ angles due to a lack of calibration of the diffractometer. Accordingly, to account for this, we used the $\gamma$-Fe peak at $27.375^{\circ} 2 \theta$ (of the stainless electrode) as an internal standard. 


\section{Scanning Electron Microscopy (SEM) preparation}

For SEM investigation, the stainless steel electrodes were gold sputtered as received. The solids from conductivity experiments were prepared by placing a portion of the filter paper onto a carbon coated SEM stub and gold sputtering the surface. The samples were then viewed using a Philips XL30 machine.

\section{FTIR experiments}

The infrared spectra method has been previously described [23]. Briefly, spectra were obtained on a Bruker IFS 66 instrument using the Horizontal Attenuated Total Reflection (HATR) accessory. The resolution was $4 \mathrm{~cm}^{-1}$ with an aperture of $12 \mathrm{~mm}, 256$ scans were obtained for all spectra. Barium sulfate was prepared such that the resultant particles had a mean radius of $\sim 270 \mathrm{~nm}$ (using a Malvern Mastersizer) with $90 \%$ of particles below $560 \mathrm{~nm}$ and a surface area of $7.4 \mathrm{~m}^{2} / \mathrm{g}$ (using the BET method, nitrogen as the carrier gas). Solutions of $\mathrm{pH} 5,6,7$ and 8 were prepared by adding the minimum volume of hydrochloric acid or sodium hydroxide required. The organic solutions were analysed by HATR using a zinc selenide crystal. Approximately $1 \mathrm{~mL}$ of each solution was introduced on to the crystal surface using a Pasteur pipette and the crystal cleaned between solutions using milliQ water and ethanol. The adsorbed organic spectrum was obtained by subtracting the spectrum of barium sulfate in solution from the spectrum of the organic and barium sulfate in solution at a given $\mathrm{pH}$.

\section{Electrochemical Impedance Spectroscopy (EIS)}

The EIS measurements used a Princeton Applied Research PARSTAT 2263 portable potentiostat. Many repeats of the EIS and SR-GIXRD runs were performed. It must be noted that EIS and SRGIXRD data were obtained by stopping the pump and simultaneously acquiring the EIS and SR-GIXRD data on the stagnant cell. After completion of the experiment, the electrode was gently washed, air dried 
and stored in a plastic container (to avoid dust particles) prior to SEM investigation on return to Perth, Australia. However, inductance loops were difficult to understand. The EIS studies were, therefore, fitted using equivalent circuitry software (Zview, Scribner Assoc. Inc.) in order to obtain relevant time constants.

\section{RESULTS AND DISCUSSION}

\section{Microscopy results}

The particles formed on the electrode surface were rectangular in shape (Figure 4a), typical of particles formed in the absence of additives at this concentration and temperature [23]. Their orientations were random on the substrate surface and large aggregates were observed with much of the stainless steel surface still bare. The particles on the stainless steel surface are of the same morphology as those precipitated in the bulk solution as seen in Figure $4 \mathrm{~b}$. The size of the particles is unaffected by the stainless steel electrode, as both systems show polydisperse particles of $\leq 5 \mu \mathrm{m}$ in the long axis. Some of the particles on the electrode appear to be marginally larger. The interaction with the stainless steel surface, therefore, appears to be weak, as it also does not induce a preferred orientation of precipitation for the barium sulfate on its surface. The amount of bare electrode remaining, however, means that the electrode behaviour is not expected to be appreciably changed by the presence of such a non-uniform scale on its surface.

The barite particles formed in the presence of NTA onto the stainless steel electrode (see Figure 5) after a total time of 4 hours precipitation ( 2 hours subsequent to the barium sulfate spike) are quite rounded and tended to aggregate. As expected, no preferred orientation was observed for these barium sulfate particles by SR-GIXRD. The particles obtained from the conductivity experiment are also shown in Figure 5. The particles formed in solution are the same morphology but, clearly, larger than those formed on the stainless steel electrode. Thus, in the presence of NTA, the stainless steel surface appears to be interacting with barium sulfate to a greater degree as it appears to influence the size of particles 
significantly.

The particles formed in the presence of NTMP (Figure 5) are the same morphology as those observed at lower temperatures [24]. These particles have been previously shown by TEM to be (100) discs [24]. Once again, the particles formed in solution (Figure 5) are slightly larger than those formed on the electrode surface. This system did show preferred orientation in the SR-GIXRD, which would be expected given the flat, disc-like shape and the predominance of the particles crystallized in the vertical position. As with NTA, we would suggest that the surface interaction is stronger in the presence of NTMP than in the control since particle size appears to be affected. The crystallization of the barite in a particular orientation on the electrode only when NTMP is present suggests that the NTMP interacts with the barite particles (altering the morphology) and with the surface (the NTMP is promoting a particular plane to crystallize). Thus, the crystal grows in a preferred way on the electrode. It is possible that the NTA and NTMP concentrations are higher on the electrode surface compared to the bulk and this may lead to an enhanced effect on the barite particle size. This hypothesis is supported by the crystallization work on NTA that shows as the concentration of NTA is increased, the particle size of barium sulfate precipitated is decreased [23]. The preferred orientation effects by NTMP are also supported by literature that shows both carboxylate and phosphonate molecules are known to adsorb onto stainless steel $[31,32]$. Thus, when inhibitor molecules are present, a three way equilibrium is established whereby some inhibitor molecules are in solution, some on the barium sulfate particles and some are on the electrode surface. The amount of each depends on the relative strengths of these interactions; for NTA the complex in solution is expected to be more significant than for NTMP since NTA is a strong chelating agent.

\section{SR-GIXRD}

It was found that barite scale formation onto stainless steel required a high flow rate, which has been previously reported [33]. However, it is also well known that turbulent conditions can also lead to scale 
detachment [34]. It should be noted that the scale can be formed by both direct growth on the surface and by cementation of particles onto the surface. Thus, the reasons for high flow rates promoting scale formation can be explained in terms of mass transport. In our particular experimental set-up, the particles were observed to settle within the reservoir after a relatively short period of time ( $<1$ hour). Thus, the evolution of the barite scale by particle cementation should have decreased with time. This can only mean that the dominant mechanism of scale formation at times greater than 1 hour is by particle growth. This also implies that the contribution of particulate matter in the solution to the SRGIXRD patterns was negligible, particularly for the diffraction patterns obtained at $>1$ hour. Note, a SR-GIXRD of the system almost immediately after the onset of barite precipitation in solution also revealed an absence of barite particles, thereby further supporting the notion that the observed SRGIXRD patterns are due to barite crystallization on the electrode surface.

The SR-GIXRD of the solids formed on the electrode (Figure 6, control) show that barium sulfate is present (barium sulfate peaks shown as lines within the XRD plot and tabulated in Table 1). Some barium sulfate peaks are absent while others appear slightly shifted. It was found that this shift is an artifact of the sloping background, however, subtraction of the kapton peaks was not performed due to negative peaks which then arose around our calibration peak. Those barite SR-GIXRD peaks expected around the $2 \theta$ value of $27-28^{\circ}$ may or may not be present, the electrode peak in this region is large and prevents a meaningful assignment of other peaks. Of those peaks not associated with barite, the new peaks observed correlated best to the presence of $\mathrm{Fe}_{2}\left(\mathrm{SO}_{4}\right)_{3}$ (PDF file number 75-1767 showing peaks at $2 \theta 18.15,19.93,26.71,28.77$ and $\left.30.97^{\circ}\right)$. The peak at $2 \theta=12.59^{\circ}$ did not match any of the iron (III) sulfate files but could be indicative of iron (II) sulfate. However, since there were no other peaks visible (for the control run) that matched the iron (II) sulfate this assignment is tentative. Since no Fe(III) is being added to this system (only barium, chloride, sulfate and sodium ions are added) this shows that the stainless steel electrode was undergoing an electrochemical reaction whereby the Fe oxidized to $\mathrm{Fe}(\mathrm{III})$, albeit at very low levels. 
The effect of NTA inhibitor:

Firstly, NTA was added after scale had been deposited on the electrode to assess the impact of NTA on barium sulfate dissolution (chelators such as EDTA and NTA are shown to dissolve scales over time [35-37]). It was found that dissolution did not occur to an appreciable level on the timescale of the experiment. Quite different was the behaviour when NTA was added prior to scale formation. Precipitation in this system was considerably inhibited (data not shown) until the additional barium sulfate spike after 2 hours.

From the SR-GIXRD pattern (in Figure 6, NTA) it is found that many more barite peaks are being observed. This is no doubt due to the rounded nature of the particles (see Figure 5 above) allowing more planes to be accessed by the X-ray beam. In addition, many peaks are stronger in the presence of NTA than in the control run, however as can be seen from peaks such as those at $\sim 16$ and $17^{\circ}$, most are broader than the control peaks even though they are stronger. This is no doubt due to the fact that smaller barite particles are crystallized when NTA is present. There are also several peaks observed in the presence of NTA that are not due to barium sulfate and are absent in the control. It was found that many of the higher angle peaks were easily assigned to $\mathrm{Fe}_{2}\left(\mathrm{SO}_{4}\right)_{3}$ as observed for the control, but below the detection limit. In the lower angle region, the $13,14.4$ and $15.7^{\circ}$ peaks could now be assigned to $\mathrm{FeSO}_{4}$ (PDF file number 73-1057). The stronger peaks observed suggests that there is more material on the surface of the electrode than in the case of the control. Thus, on spiking and increasing the supersaturation, the amount of precipitate is greater than in the control situation. This can be understood from some recent results [23] that show that NTA does not perform well as an inhibitor at elevated temperatures. Even more interesting, however, is the presence of iron sulfate species (both $\mathrm{Fe}^{2+}$ and $\mathrm{Fe}^{3+}$ ) on the electrode surface. The corrosion of stainless steel is low, and the iron sulfate peaks in the control spectrum were weak and difficult to detect. Thus, the dissolution of the iron species such that they are easily observed in the SR-GIXRD pattern must be promoted in the presence of NTA. This is 
perhaps due to the better co-ordinating power of the fully de-protonated NTA molecule (recall, precipitation was carried out at $\mathrm{pH} 10$ ) to bind to $\mathrm{Fe}^{2+}$ and $\mathrm{Fe}^{3+}$ ions, which are subsequently released to the solution as a complex (i.e. Fe-NTA complex). In turn, this would cause the equilibrium between $\mathrm{Fe}^{0}$ and oxidized Fe to re-establish, resulting in an increased oxidized iron level over time.

The effect of NTMP inhibitor:

The presence of a barium sulfate scale prior to the addition of NTMP did not result in any observable dissolution of the scale on stainless steel (as was found for NTA). NTMP, however, was found to inhibit precipitation completely at $\mathrm{pH} 7$ and this was confirmed by the conductivity results (data not shown). Only after spiking the solution at 2 hours with additional barium sulfate was precipitation observed.

As can be seen from Figure 6, the same peaks are evident in the SR-GIXRD pattern when NTMP is present as in the control SR-GIXRD at a comparable length of time. Some notable differences can also be observed:

- Most of the peaks in the presence of NTMP are smaller and broader and

- the (200) XRD peak is very weak if not absent (in these spectra the (200) peak should be present at $2 \theta=12.93^{\circ}$ )

As for NTA, the broader diffraction peaks can be interpreted as being due to the smaller crystallite sizes formed when NTMP is present (control particles are of the order of $\sim 5-10 \mu \mathrm{m}$ while in the presence of NTMP they are 1-2 $\mu \mathrm{m}$ in diameter and very thin -we estimate, at most in the hundreds of $\mathrm{nm}$, see Microscopy section above). The smaller peak heights can be understood in terms of the smaller amount of scale deposited when NTMP is present compared to when it is absent.

\section{Simultaneous EIS data from stagnant cell}

As stated before, the simultaneous EIS spectra taken with the SR-GIXRD measurements showed some inductance effects that required circuit fitting in order to properly interpret. Figure 7 shows a schematic 
of the system and the corresponding electrochemical processes that might be occurring. This data has been modeled on that used by Devos et al., [7] (Figure 7a) with some noteworthy changes:

1. An induction element and resistance was added to model our inductance loops.

2. The charge transfer resistance of water was omitted since our electrode was not polarized.

3. The impedance of the diffusion layer for oxygen was so low as to be negligible in our system and was therefore omitted (as was also found in [7]).

4. A pore resistance was not necessary as the scale formed was not homogenous on the electrode surface and therefore ions did not need to diffuse through the scale pores (see Figure 4 and the related text). That is, the circuit for the bare electrode is essentially the same circuit used to model the 'scaled' electrode because the surface area of scale formed was too small to require the inclusion of pore resistances etc..

$\mathrm{R}_{\mathrm{sol}}$ corresponds to the solution resistance and $\mathrm{R}_{\mathrm{ct}}$ to the charge transfer resistance. An example of the fit to the data using this circuit is shown in Figure 8. The y-axis has been expanded to emphasise any differences. All of the parameters used are tabulated in Table 2. In the following discussion, we note that the charge transfer resistance is related to the inverse of the corrosion rate; that is, if charge can move freely corrosion will be more likely while if the resistance to charge movement is higher, corrosion will be impeded.

It was found that, using this analysis, the charge transfer resistance decreased slightly with time for the barium sulfate scale formation on the electrode without inhibitors present, presumably via the action of sulfate on the electrode. The diffusion layer around the barite particles is expected to be enriched (w.r.t. the bulk) with sulfate ions, and this would be expected to interact with the electrode surface. This is confirmed by the observation of iron (III) sulfate solids in the SR-GIXRD spectrum. That is, the presence of sulfate has caused iron metal in the electrode to oxidize and form iron (III) sulfate and this 
is a thermodynamically favourable process [38].

When NTA was present the charge transfer resistance was significantly lower than for the control run but showed a slight increase over a 9 hour period. These results are in good agreement with the SRGIXRD results that show an increase in iron mineral solids when NTA is present (greater Fe(II) and Fe(III) sulfate solids).

When NTMP is added after scale has been deposited, a large increase in the charge transfer resistance is found. This is also observed when NTMP is added prior to barium sulfate precipitation and confirms that the behaviour of the electrode is only marginally impacted by the formation of the barium sulfate scale (due to the non-uniform nature of the solids covering only a small surface area of the electrode). For NTMP, the charge transfer resistance showed a decrease over 9 hours to a value similar to the control. As expected, a larger charge transfer resistance in the presence of NTMP compared to the control correlated well with the lower solids deposited when NTMP was present (prior to film formation) as assessed by the SR-GIXRD results. Thus, overall, the stagnant flow EIS results are well supported by the stagnant flow SR-GIXRD results.

\section{FTIR evidence}

In an effort to obtain information on the adsorption of the inhibitors onto the surfaces encountered in this work, we undertook FTIR analysis. The results for NTA on barium sulfate are given in reference [23]. The results showed that NTA chemisorbs onto barium sulfate and adsorbs stronger at higher $\mathrm{pH}$. Literature on the adsorption of carboxylates onto stainless steel can be found in reference [31] while for adsorption of alkylphosphonates onto stainless steel we direct the reader to reference [32]. The infrared analysis of phosphonates on barium sulfate is particularly difficult due to the overlapping of the region where phosphonate and sulfate bands are found. Solution spectra did not suffer from sulfate band interference and are shown in Figure 9. According to the speciation of NTMP [39], two protons are essentially lost on increasing the $\mathrm{pH}$ to 8 . At $\mathrm{pH} 8$, the dominant species is the mono-protonated species. 
This supports the FTIR results (Figure 9, in solution) where the band at $\sim 915$ and $\sim 1190 \mathrm{~cm}^{-1}$ disappears with increasing $\mathrm{pH}$. These bands, are either due to the vibration of $\mathrm{P}=\mathrm{O}$ and $\mathrm{PO}_{2}$ groups [40] or are due to $\mathrm{P}=\mathrm{O}$ and $\mathrm{P}-\mathrm{OH}$ groups [41]. These bands are, therefore, due to protonated or non-ionic species vibrations. As the $\mathrm{pH}$ rises the bands at $\sim 1090$ and $970 \mathrm{~cm}^{-1}$ increase. These bands are due to $\mathrm{PO}_{3}{ }^{2-}$ and/or $\mathrm{PO}_{3} \mathrm{H}^{1-}$ groups, that is, the ionised $\mathrm{P}_{-} \mathrm{O}^{-}$moiety as expected $[40,41]$.

Once adsorbed onto barium sulfate, the NTMP spectrum is difficult to subtract from the overall spectrum due to the overlap with sulfate peaks. For $\mathrm{pH} 7$ and 8 where the amount of barium sulfate on the ZnSe crystal closely matches the control samples, the spectra were subtracted and the following are shown in Figure 9 (adsorbed). The adsorbed phosphonate spectrum at $\mathrm{pH} 8$ is very similar to the $\mathrm{pH} 8$ spectrum in solution. Here, however, the $\mathrm{PO}_{3}{ }^{2-}$ stretch appears to have shifted to $\sim 1100 \mathrm{~cm}^{-1}$. This increase is undoubtedly related to the interaction of the phosphonate group with the barium sulfate, as found for methylphosphonic acid and goethite [40] and is attributed to adsorbed species [41]. There are two other notable differences between the adsorbed and solution spectra:

i) The peak at $\sim 1200 \mathrm{~cm}^{-1}$ is stronger (suggesting that there are more $\mathrm{P}=\mathrm{O}$ vibrations); and

ii) The doublet at $\sim 1600-1550 \mathrm{~cm}^{-1}$ is replaced with a single but weak peak. Botelho do Rego et al., [41] suggests this is due to hydrogen bonding with water molecules.

The amount of NTMP adsorbed onto barite was determined at $25{ }^{\circ} \mathrm{C}$ by measuring an adsorption isotherm. This showed that approximately $430 \mu \mathrm{g}$ per $\mathrm{m}^{2}$ NTMP is adsorbed [42]. This is about a factor of 2 larger than the value of NTMP adsorbed onto goethite [43]. This could, however, be due to the fact that NTMP adsorbs to a greater degree on barite than goethite. Also, a fit to the Langmuir isotherm for the data (i.e. $\theta=\mathrm{kc} \Gamma /(1+\mathrm{kc})$ where $\mathrm{k}$ is a constant, $\mathrm{c}$ is the residual concentration in solution and $\Gamma$ is the monolayer adsorption level) gave a $\mathrm{k}$ value of $\sim 8$, noting that a $\mathrm{k}$ value $>1$ suggests that adsorption is favoured over desorption [44]. This confirms that adsorption of the NTMP is strong and favoured on barium sulfate. 


\section{Conclusions}

It was found that SR-GIXRD was able to reveal the formation of barium sulfate scale on the electrode surface despite its discontinuous nature and small mass. Furthermore, SR-GIXRD was able to show the trend with crystallite size of the particles in the deposited scale in the presence of inhibitors. The SRGIXRD technique, however, did not always show the expected correlation with barium sulfate morphology (i.e. in the case of NTMP, the (100) face was not observed despite the morphology of the particles being dominated by the (100) face but this was probably due to their preferred orientation on the electrode). In addition, SR-GIXRD was able to show that there was no preferred orientation effects in the presence of NTA during barite precipitation, while there was preferred orientation effects when NTMP was present during barite precipitation. In this regard, the SR-GIXRD did correlate with the effect of the additives on the morphology of the resultant particles.

The simultaneous EIS data showed that the same trends were also observed in the electrochemical behaviour. In the presence of NTA during barium sulfate scaling, stronger iron sulfate peaks were observed and a lower charge transfer resistance was found. This would suggest that, in the presence of NTA, oxidized iron is being leached from the electrode surface to a greater extent than in the control situation. When NTMP was present during precipitation, it appeared to protect the surface both from corrosion (higher charge transfer resistance) and from scale formation (less barium sulfate solids being formed). Thus, clearly inhibitors can have differing properties with regard to their scale inhibiting characteristics and their corrosion inhibiting characteristics.

FTIR and adsorption isotherm data have shown that the NTMP molecule can chemisorb to the barite surface and that NTMP has a strong affinity for the barite surface. There is also evidence via the preferred orientation effects and the impact on the charge transfer resistance (as well as previous literature [31, 32]) that both NTA and NTMP have an affinity for the stainless steel electrode.

Future plans are to undertake experiments that will involve using EIS to study $\mathrm{BaSO}_{4}$ scale formation on a system that undergoes a significant level of corrosion (e.g., carbon steel) in order to properly assess 
the impact of inhibitors on the corrosion behaviour of metal surfaces. Surface coatings (eg surfactants) are routinely used to control corrosion behaviour of metal surfaces with little fundamental knowledge as to their effect on barite scale properties or vice versa.

ACKNOWLEDGMENTS. We gratefully acknowledge that this research has been supported under the Australian Government's Cooperative Research Centre (CRC) Program, through the Parker CRC for Integrated Hydrometallurgy Solutions. The SR-GIXRD work was performed at the Australian National Beamline Facility (ANBF) with support from the Australian Synchrotron Research Program, which is funded by the Commonwealth of Australia under the Major National Research Facilities Program. We also thank Drs. Garry Foran and James Hester at the ANBF for support on the SR-GIXRD work. Finally, we thank Brenda Rohl for her hard work in obtaining the adsorption isotherm data of NTMP on barite, and Bill Richmond, Jonathon Morton and Nicole Gorham for their help in collecting SR-GIXRD spectra.

\section{REFERENCES}

[1] Kermani, M. B., Morshed, A. Corrosion 2003 59(8) 659.

[2] Jones, D. A., Principles and Prevention of Corrosion, $2^{\text {nd }}$ Ed., 1996 Prentice-Hall, Upper Saddle River N. J., USA.

[3] Jones, F., Rohl, A. L., Ogden, M. I., Parkinson, G. M. Materials Forum 200125116.

[4] Fang, B. Y., Atrens, A., Wang, J. Q., Han, E. H., Zhu, Z. Y., Ke, W. J. Materials Sci. 200338127

[5] Mathiyarasu, J., Boopathi, C., Subramanian, P., Palaniswamy, N. Anti-Corrosion Methods and Materials 2001 48(6) 381.

[6] Marín-Cruz, J., Cabrera-Sierra, R., Pech-Canul, M. A., González, I. Electrochimica Acta 200651 
[7] Devos, O., Gabrielli, C., Tribollet, B. Electrochimica Acta 2006511413.

[8] Marín-Cruz, J., Cabrera-Sierra, R., Pech-Canul, M. A., González, I. J. Appl. Electrochmistry 2004 34337.

[9] Devos, O., Gabrielli, C., Tlili, M., Tribollet, B. J. Electrochem. Soc. 2003 150(7) C494.

[10] Gabrielli, C., Keddam, M., Khalil, A., Rosset, R., Zidoune, M. Electrochimica Acta 1997 42(8) 1207.

[11] Demadis, K. D., Mantzaridis, C., Raptis, R. G., Mezei, G. Inorg Chem. 2005 44(13) 4469.

[12] De Marco, R., Pejcic, B., Prince, K., van Riessen, A. Analyst 2003128742.

[13] De Marco, R, Jiang, Z.T., John, D., Sercombe, M., Kinsella, B. Electrochim. Acta 2007 52(11) 3746

[14] Amjad, Z. Water Treatment 1994947.

[15] Sorbie, K. S., Mackay, E. J. J. Petroleum Sci. Eng. 20002785.

[16] Graham, G. M., Boak, L. S. and Sorbie, K. S. International Symposium on Oilfield Chemistry, Society of Petroleum Engineers, USA. 1997 SPE37273.

[17] Schwarzer, H.-C., Peukert, W. Chem. Eng. Technol. 2002 25(6) 657.

[18] Stephen, H., Stephen, T. "Solubilities of inorganic compounds" Pergamon Press, London, 1979 Vol 1 part 1, pp157.

[19] Olsson, C. O. A., Landolt, D., Electrochimica Acta 2003481093.

[20] Jones, F., Clegg, J., Oliveira, A., Rohl, A. L., Ogden, M. I., Parkinson, G. M. CrystEngComm. 
[21] Coveney, P. V., Davey, R. J., Griffin, J. L. W., He, Y., Hamlin, J. D., Stacckhouse, S. and Whiting, A. J. Am. Chem. Soc. 200012211557.

[22] Bromley, L. A., Cottier, D., Davey, R. J., Dobbs, B., Smith, S. and Heywood, B. R. Langmuir 199393594.

[23] Jones, F., Oliveira, A., Rohl, A. L., Ogden, M. I., Parkinson, G. M. CrystEngComm 20068869.

[24] Jones, F., Richmond, W. R., Rohl A. L. J. Phys. Chem. B 20061107414.

[25] Kautek, W., Geub, M., Sahre, M., Zhao, P., Mirwald, S. Surf. Interface Anal. 199725548.

[26] Sathiyanarayanan, S., Sahre, M., Kautek, W. Electrochim. Acta 1998432985.

[27] Sathiyanarayanan, S., Sahre, M., Kautek, W. Corr. Sci. 1999411899.

[28] De Marco, R., Jiang, Z.-T., Martizano, J., Lowe, A., Pejcic, B., van Riessen, A. Electrochim. Acta 2006515920.

[29] Chen, J. M., Lu, K. T., Lee, J. M., Haw, S. C. Surface Science 2006 600(18) 3544.

[30] Kim, J.J., Ikenaga, E., Kobata, M., Takeuchi, A., Awaji, M., Makino, H., Chen, P. P., Yamamoto, A., Matsuoka, T., Miwa, D., Nishino, Y., Yamamoto, T., Yao, T., Kobayashi, K. Applied Surface Science 2006 252(15) 5602.

[31] Nagayasu, T., Yoshioka, C., Imamura, K., Nakanishi, K. J. Colloid and Interface Sci. 2004279 296.

[32] Raman, A., Dubey, M., Gouzman, I., Gawalt, E. S. Langmuir 2006226469.

[33] Quddus, A., Allam, I. M. Desalination 2000127219. 
[34] Bansal, B., Müller-Steinhagen, H. J. Heat Transfer 1993115584.

[35] Rajabalee, F. J. M. Spectrochimica Acta 1974 30A 891.

[36] Dunn, K., Yen, T. F. Environ. Sci. \& Technol. 1999 33(16) 2821.

[37] Wang, K.-S., Resch, R., Dunn, K., Shuler, P., Tang, Y., Koel, B. E., Yen, T. F. Langmuir 2000 16649.

[38] Estimation of ' $\mathrm{n}$ ' $\mathrm{K}$ ' values at higher temperatures: $\mathrm{P}$. May and $\mathrm{K}$. Murray, http://jess.murdoch.edu.au/jess/jess_home.htm. This is an online database containing an extensive list of protonation and complexation constants for a variety of ligands. There is also a facility for estimating complexation constants for those temperatures or ionic strength conditions for which there is no data.

[39] Speciation curves were calculated using the Hyss program (L. Alderighi, P. Gans, A. Ienco, D. Peters, A. Sabatini and A. Vacca, "Hyperquad simulation and speciation (HySS): a utility program for the investigation of equilibria involving soluble and partially soluble species", Coordination Chemistry Reviews, 1999184 311-318). Equilibrium constant data, for protonation reactions, were obtained from the on-line JESS thermodynamic database given above in [38].

[40] Barja, B. C., Tejedor-Tejedor, M. I., Anderson, M. A. Langmuir 1999152316.

[41] Botelho do Rego, A. M., Ferraria, A. M., El Beghdadi, J., Debontridder, F., Brogueira, P., Naaman, R., Rei Vilar, M. Langmuir 2005218765.

[42] The adsorption isotherm of NTMP was determined by the difference method. Namely, $2.5 \mathrm{~mL}$ of an $8 \% \mathrm{wt} / \mathrm{vol}$ slurry of barium sulfate in water was added to a given quantity of the stock solution of NTMP and made up to a total volume of $10 \mathrm{~mL}$. Both the slurry and the stock solution had been preadjusted to $\mathrm{pH} 8$ using $\mathrm{NaOH}$ and equilibrated to $25^{\circ} \mathrm{C}$. After 24 hours equilibration time the $\mathrm{pH}$ was re-checked and an aliquot of the supernatant was obtained for P analysis using ICP-AES. 
[43] Novack, B., Stone, A. T. J. Colloid \& Interface Sci. 199921420.

[44] Lyklema, J. in Fundamentals of Interface and Colloid Science, 1995 Academic Press Limited, London. 


\section{TABLES}

Table 1. Barium sulfate SR-GIXRD peaks from literature (PDF file number 83-1718)

\begin{tabular}{|c|c|c|}
\hline $2 \theta$ value (for $\lambda=1 \AA$ ) & d spacing & hkl \\
\hline 10.29 & 5.576 & 101 \\
\hline 12.93 & 4.440 & 200 \\
\hline 13.23 & 4.340 & 011 \\
\hline 14.74 & 3.900 & 111 \\
\hline 16.06 & 3.576 & 002 \\
\hline 16.69 & 3.442 & 210 \\
\hline 17.33 & 3.317 & 102 \\
\hline 18.54 & 3.101 & 211 \\
\hline 20.31 & 2.834 & 112 \\
\hline 21.12 & 2.726 & 020 \\
\hline 26.14 & 2.209 & 221 \\
\hline 27.25 & 2.120 & 113 \\
\hline 27.48 & 2.104 & 312 \\
\hline 28.13 & 2.056 & 410 \\
\hline
\end{tabular}


Table 2. Parameter values for circuit fitting of EIS data.

\begin{tabular}{|c|c|c|c|c|c|c|c|}
\hline & $\begin{array}{l}\mathrm{R}_{\mathrm{sol}} \\
(\Omega)\end{array}$ & $\begin{array}{l}\mathrm{R}_{\mathrm{ct}} \\
(\Omega)\end{array}$ & $\begin{array}{l}\mathrm{R}_{\mathrm{L}} \\
(\Omega)\end{array}$ & $\begin{array}{c}\mathrm{L} \\
(\mu \mathrm{H})\end{array}$ & $\begin{array}{l}\mathrm{Q}\left(\mathrm{x} 10^{-10}\right. \\
\left.\Omega^{-1} \mathrm{~s}^{\mathrm{n}}\right)\end{array}$ & ?E & $\begin{array}{c}\chi^{2} \\
\text { (goodness } \\
\text { of fit) }\end{array}$ \\
\hline Control- & & & & & & & \\
\hline $\begin{array}{l}0 \text { hours } \\
10 \text { hours }\end{array}$ & $\begin{array}{l}\quad 130 \\
\text { fixed for all } \\
\text { subsequent } \\
\text { data }\end{array}$ & $\begin{array}{l}35324 \\
28343\end{array}$ & $\begin{array}{l}6422 \\
4007\end{array}$ & $\begin{array}{l}15.24 \\
8.792 \\
\end{array}$ & $\begin{array}{l}\quad 2.725 \\
\text { fixed for all } \\
\text { subsequent } \\
\text { data }\end{array}$ & $\begin{array}{l}1.031 \\
\text { fixed for all } \\
\text { subsequent } \\
\text { data }\end{array}$ & $\begin{array}{l}0.116 \\
0.181\end{array}$ \\
\hline 18hours & & 16530 & 2685 & 3.419 & & & 0.430 \\
\hline $\begin{array}{l}\text { NTA- } \\
0 \text { hours } \\
9 \text { hours }\end{array}$ & & $\begin{array}{l}14911 \\
16424\end{array}$ & $\begin{array}{l}2469 \\
2872\end{array}$ & $\begin{array}{l}3.794 \\
3.275\end{array}$ & & & $\begin{array}{l}0.270 \\
0.603\end{array}$ \\
\hline $\begin{array}{l}\text { NTMP- } \\
2 \text { hours }\end{array}$ & & 50484 & 28960 & 41.7 & & & 0.101 \\
\hline $\begin{array}{c}9 \text { hours } \\
\text { added after }\end{array}$ & & 34181 & 26141 & 15.62 & & & 0.131 \\
\hline $\begin{array}{c}\text { scale } \\
\text { formation, } \\
\text { (18hrs) }\end{array}$ & & 54904 & 3668 & 20.75 & & & 0.128 \\
\hline
\end{tabular}


FIGURE CAPTIONS

Figure 1. Schematic of perspex cell used to monitor scale formation via SR-GIXRD in-situ

Figure 2. Structures, abbreviations and full names of inhibitors used in this study

Figure 3. SR-GIXRD spectra obtained for the cell with Katpon film (spectra offset for clarity)

Figure 4. SEM images of a) barite on stainless steel electrode b) barite from control conductivity run at $60{ }^{\circ} \mathrm{C}$ (porous background is filter membrane)

Figure 5. Barite formed on stainless steel when NTA is present, barite formed in the presence of NTA from a conductivity run (porous background is due to filter paper), barite particles formed on stainless steel in the presence of NTMP and barite formed in the presence of NTMP from a conductivity run. All data are at $60{ }^{\circ} \mathrm{C}$. (scale bars are $2 \mu \mathrm{m}$ for stainless steel surface and $5 \mu \mathrm{m}$ for particles from conductivity)

Figure 6. SR-GIXRD obtained after 10 hours of barite formation, with and without inhibitors present (lines show barium sulfate peak positions)

Figure 7. Schematic showing circuit diagram that was used to simulate our system; a) circuit used for the bare electrode in [7] with the oxygen impedance and charge resistance removed (since the electrode in this work was not polarized) and b) introduction of a resistance and inductance element to account for impedance loops in our data $(\mathrm{R}=$ resistor, $\mathrm{CPE}=$ constant phase element, $\mathrm{L}=$ Inductance $)$

Figure 8. a) Best fit to data (barite precipitation on stainless steel in the presence of NTMP after 2 hours) b) Worst fit to data (barite precipitation on stainless steel in the presence of NTA after 9 hours)

Figure 9. HATR spectra of dissolved NTMP at different pHs (in solution) and adsorbed NTMP on barium sulfate (adsorbed). Spectra have been offset for clarity 